\title{
High-Resolution 3D FIB-SEM Image Analysis and Validation of Numerical Simulations of Nanometre-Scale Porous Ceramic with Comparisons to Experimental Results
}

\author{
N. J. Welch ${ }^{1}(\mathbb{D})$ F. Gray ${ }^{1}$ - A. R. Butcher ${ }^{2}$. \\ E. S. Boek ${ }^{1,3}$ - J. P. Crawshaw ${ }^{1}$
}

Received: 16 March 2016 / Accepted: 6 April 2017 / Published online: 4 May 2017

(C) The Author(s) 2017. This article is an open access publication

\begin{abstract}
The development of focused ion beam-scanning electron microscopy (FIB-SEM) techniques has allowed high-resolution 3D imaging of nanometre-scale porous materials. These systems are of important interest to the oil and gas sector, as well as for the safe long-term storage of carbon and nuclear waste. This work focuses on validating the accurate representation of sample pore space in FIB-SEM-reconstructed volumes and the predicted permeability of these systems from subsequent single-phase flow simulations using a highly homogeneous nanometre-scale, mesoporous $(2-50 \mathrm{~nm})$ to macroporous $(>50 \mathrm{~nm})$, porous ceramic in initial developments for digital rock physics. The limited volume of investigation available from FIB-SEM has precluded direct quantitative validation of petrophysical parameters estimated from such studies on rock samples due to sample heterogeneity, large variations in recorded sample pore sizes and lack of pore connectivity. By using homogeneous synthetic ceramic samples we have shown that lattice-Boltzmann flow simulations using processed FIB-SEM images are capable of predicting the permeability of a homogeneous material dominated by 10-100 nanometre-scale pores (similar, albeit simpler, to those in natural samples) at the much larger scale where permeability measurements become practical. This result shows the LB flow simulations can be used with confidence in pores at this scale allowing future work to focus on sample preparation techniques for samples sensitive to drying and multiple FIB-SEM site selection for the population of larger-scale models for heterogeneous systems.
\end{abstract}

Keywords FIB-SEM - Lattice-Boltzmann model · Microporosity · Permeability prediction · Low permeability

$凶$ N. J. Welch

n.welch12@imperial.ac.uk

1 Department of Chemical Engineering, Qatar Carbonates and Carbon Storage Research Centre, Imperial College London, South Kensington Campus, London SW7 2AZ, UK

2 FEI, Cambridge, UK

3 Present Address: Department of Applied Mathematics and Theoretical Physics, Cambridge University, Cambridge, UK 


\section{Introduction}

The fluid flow properties of porous media samples with pore body sizes below 1 micron and low permeability are of major importance to numerous fields of study. Low permeability formations are often of significant interest in petroleum engineering applications as they form the seal, or cap rock, above hydrocarbon reservoirs (Boulin et al. 2013; Harrington and Horseman 1999; Hildenbrand et al. 2002; Schlomer and Krooss 1997; Thomas et al. 1968). They are important to carbon storage operations as a major trapping mechanism, specifically physical trapping (Amann-Hildenbrand et al. 2013; Boulin et al. 2011; Hildenbrand et al. 2004; Li et al. 2005; Wollenweber et al. 2009, 2010). Increasingly, these systems also play a large role in the behaviour of unconventional hydrocarbon recovery processes such as shale gas operations (Javadpour et al. 2007; Sakhaee-Pour and Bryant 2012). Low permeability formations are being investigated for their long-term safe containment and storage of nuclear waste as well (Ortiz et al. 2002; Van Loon et al. 2004).

Measurements of flow behaviour in tight formations are problematic for traditional core characterization apparatuses and often require specialized equipment and techniques. The time required for traditional steady-state measurements can take several hours to days for an accurate flow rate measurement to be made (Boulin et al. 2012). Advancements in permeability measurements on tight samples have been made through the use of pressure decay and other techniques to sufficiently shorten experiment time requirements beginning with the work of Brace et al. (1968) and expanded on by Hsieh et al. (1981) and Neuzil et al. (1981). However, samples of sufficient size to apply conventional permeability measurements (cores) are expensive to obtain, while small samples (cuttings and plugs) are readily available. Therefore, efforts have been made in the analysis of smaller samples for formation permeability determination and other characteristics (Luffel et al. 1993; Peng and Loucks 2016), but these methods may not provide accurate estimates of flow properties (Cui et al. 2009). These experiments still require specialized equipment development, and in this case it may be more favourable to employ imaging techniques coupled with numerical simulations instead.

Digital rock analysis (DRA) currently has the potential to predict the majority of fluid flow characteristics based on an image of the pore space of the sample in question using various numerical simulation methods (Blunt et al. 2013). This approach has become well established for reservoir rocks such as sandstone in which the pores can be imaged adequately using micro-CT (Boek and Venturoli 2010). Focused ion beam-scanning electron microscopy (FIB-SEM) imaging has recently extended the practical 3D imaging of rock pore structures to the nanoscale (Groeber et al 2006; Holzer et al. 2006; Wirth 2009). However, due to the small volume analysed by FIB-SEM, the influence of heterogeneity, variation in pore sizes, and lack of connectivity between observed pores in a majority of the samples analysed have precluded direct validation of fluid flow behaviour predicted from the pore space image by measurement at the plug or core scale (Hemes et al. 2015; Keller et al. 2013a; Desbois et al. 2011). Sample preparation techniques required for the use of the SEM environment often can also lead to damage of the natural pore space found in geologic samples due to the need to remove moisture from the sample. Several alternative developing techniques including cryogenics (Desbois et al. 2010) and resin/metal impregnation may avoid sample pore space damage and to assist in image processing and segmentation (Song et al. 2016, 2015; Holzer et al. 2006).

The current work aims to validate the predicted flow behaviour of nanometre-scale pore structures imaged by a FIB-SEM system often used in combination with other methods for 
the prediction of geologic formation properties. An important distinction should be made in the nomenclature used in studies at this scale between earth sciences and material sciences. Pores $<1 \mu \mathrm{m}$ are often described as microporous or nanoporous regions of a geologic sample in earth sciences, whereas nanoporous gas sorption studies often refer to pores strictly $<2 \mathrm{~nm}$ (Sing 1985). The pore spaces observed in this study are classified as mesoporous $(2-50 \mathrm{~nm})$ to macroporous $(>50 \mathrm{~nm})$ in material sciences, but would be designated as microporous in the context of common formation rock studies for hydrocarbon production (Cantrell and Hagerty 1999). The predicted sample permeability is compared to measurements recorded during steady-state fluid flow experiments using deionized water on 12.5-mm-diameter plugs. Synthetic ceramic samples with a homogeneous nanometre-scale pore space were chosen to ensure that the experiment and simulation were comparable despite the large difference in the sample sizes used. This allows the use of FIB-SEM imaging and numerical flow simulations to be tested in systems of pores comparable in size to those found in unconventional reservoirs and seal rocks.

\section{Methods}

\subsection{Ceramic Samples}

The two ceramic samples used in this study were obtained from Cobra Technologies B.V. with a specified "nominal mean pore size" of 150 and $50 \mathrm{~nm}$. The discs supplied had an external diameter of $50.8 \mathrm{~mm}$ with a thickness of $10 \mathrm{~mm}$. Preliminary work and the work included in this paper will show that the actual pore throat and body sizes are quite similar between the two samples which from this point will be referred to as ceramic A being the $150-\mathrm{nm}$ specified sample and ceramic B being the 50-nm specified sample. Plugs of 6 and $12.5 \mathrm{~mm}$ diameter were drilled from each ceramic disc using a diamond coring bit, using tap water as a working fluid. The cored plugs were then oven-dried for several days at $50-75^{\circ} \mathrm{C}$ and subsequently used to measure the permeability of the materials.

\subsection{Computerized Microtomography}

Micro-CT tomograms (Xradia XRM 500) were recorded for both ceramic samples to assess the homogeneity of the sample pore space. The voxel size of the resulting tomogram was $7 \mu \mathrm{m}$ resulting in recorded voxel similar in size as to that of the total recorded volume of the analysed FIB-SEM volume. In this manner, each voxel can be considered a volume average of a FIB-SEM-reconstructed volume to show the expected variation between multiple analysed FIB-SEM collection sites. A radial slice from each tomogram can be seen in Fig. 1.

The data from ceramic A were analysed by calculating the covariance, $\gamma(d)$, from an individual 2D slice using:

$$
\gamma(d)=\frac{1}{2 N(d)} \sum_{1}^{N(d)}\left[I\left(x_{i}\right)-I\left(x_{i}-d\right)\right]^{2}
$$

where $N(d)$ is the number of data pairs separated by lag, $d$, and $I$ is the image greyscale intensity at positions $x$ and $x-d$. The covariance of a single slice from the middle of the imaged volume was calculated using a simple MATLAB script using Eq. (1). The covariance was calculated on a inscribed square of the imaged plug sample to eliminate the surrounding void space. Figure 2 shows the covariogram for a single $2 \mathrm{D}$ slice in the centre of the CT 

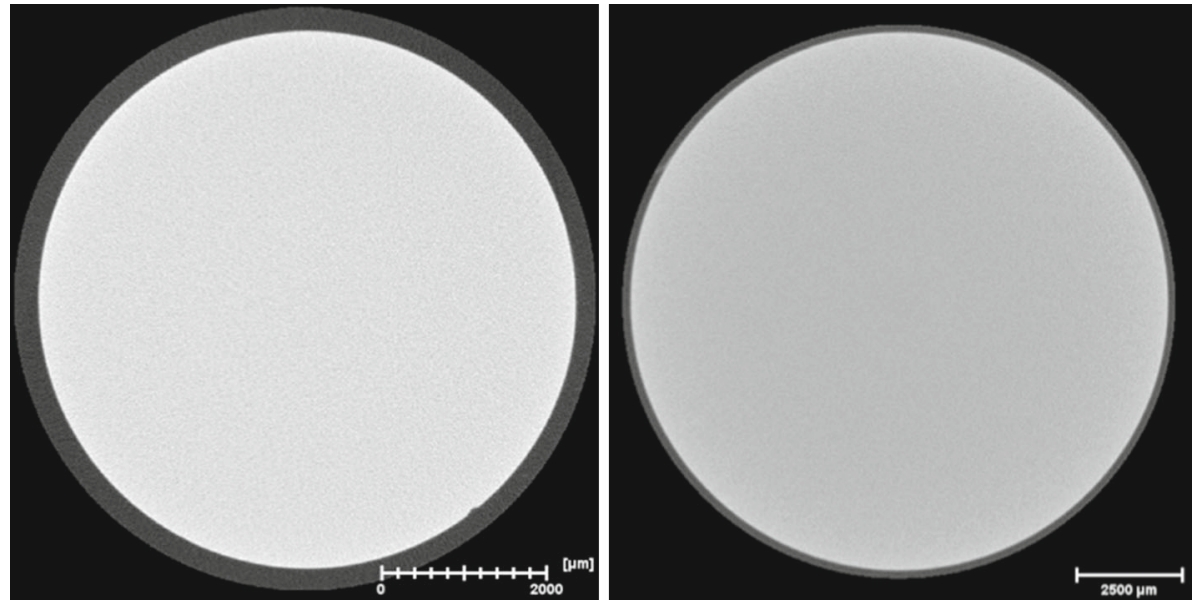

Fig. 1 (Left) Radial slice of ceramic A tomogram recorded on a 6-mm plug. (Right) Radial slice of ceramic B tomogram recorded on a $12.5-\mathrm{mm}$ plug. Both tomograms were recorded with a voxel side length of $7 \mu \mathrm{m}$

Fig. 2 Covariogram for ceramic A sample in two orthogonal directions

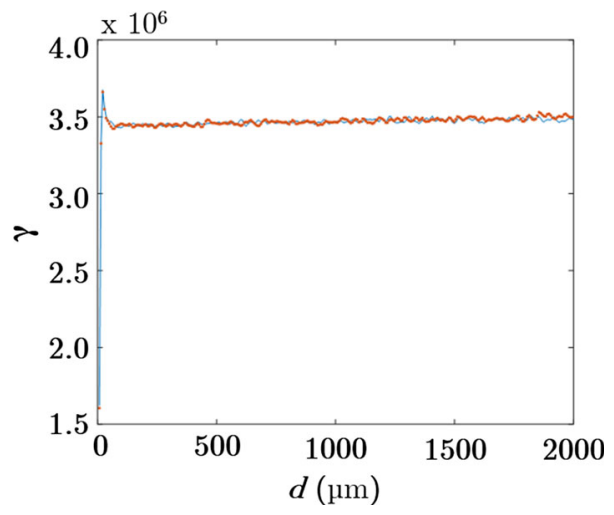

volume. The covariance approached the asymptote value within a few pixels and remained stable out to a distance of $2 \mathrm{~mm}$ showing that the ceramic has little apparent structure at a scale bigger than $20 \mu \mathrm{m}$. This length is rather small in comparison with the recorded voxel size, allowing for only the consideration of 2-3 voxels that may be of little significance beyond the noise of the recorded images. It has also been shown in the work of Hemes et al. (2015) that the characteristic length scale as determined from covariogram analysis can be influenced by the analysed image voxel or pixel side length.

\subsection{SEM and FIB-SEM Imaging}

Scanning electron microscopy (SEM) was conducted in the Electron Microscopy Suite at Imperial College London. Surface scans were recorded for each ceramic sample using secondary electron imaging. Prior to imaging samples were embedded in epoxy to be held in place during mechanical polishing. Samples were then polished to a final finish using a $1-\mu \mathrm{m}$ polycrystalline diamond abrasive suspension. Surface images of each ceramic sample can be seen in Figs. 3 and 4. 


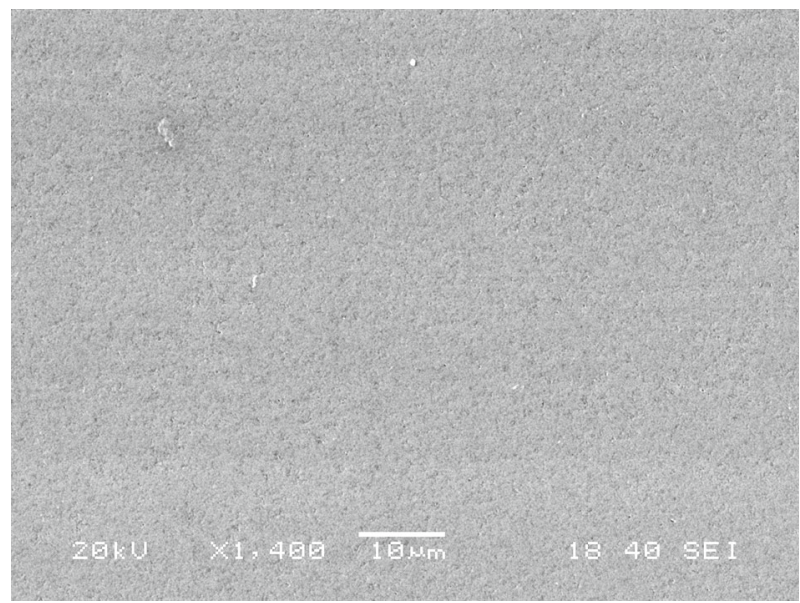

Fig. 3 SEM image of polished surface of ceramic A

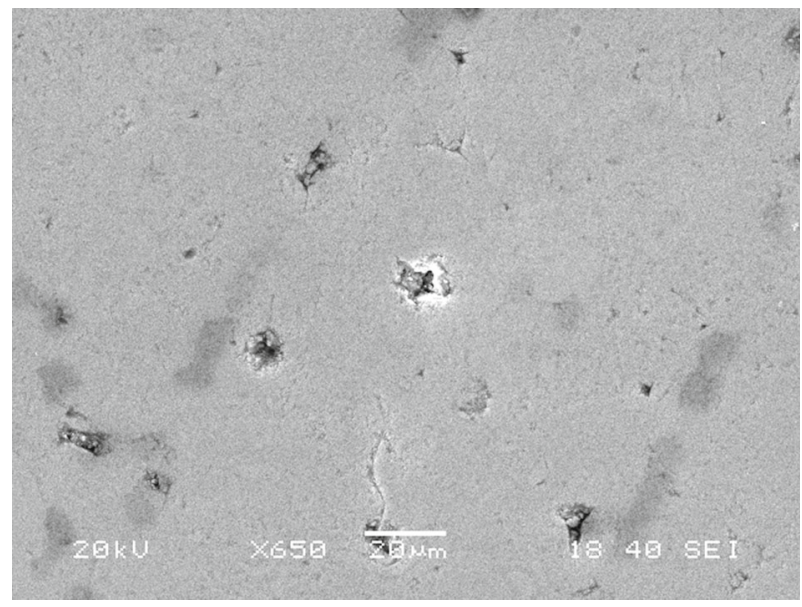

Fig. 4 SEM image of polished ceramic B

These polished surface images show that, in agreement with the previous micro-CT imaging, ceramic A appears homogeneous with no visible pore space at the micron level. Ceramic B polished surface scans, however, show numerous sporadic larger than expected pores in the 10-20 $\mu \mathrm{m}$ range exist in the sample. No significant effect on the measured sample permeability should be caused by disconnected macropores, and this structure also appears quite similar to the pore space found in geologic samples with a majority of the connected pore space existing only at the nanometre scale (Hemes et al. 2015).

Small fragments of each material were analysed at FEI's Nanoport Facility in Eindhoven, the Netherlands, by FIB-SEM imaging. Each sample was thinly coated with platinum and mounted on a platform using silver paste to both secure it in place and provide a highly conductive path to help prevent charging effects. All images were obtained on an FEI Helios NanoLab G3 Dual Beam. Initial SEM scans of the fractured sample surface, an example of which is shown in Fig. 5, were used to find suitable regions for the FIB-SEM imaging where 


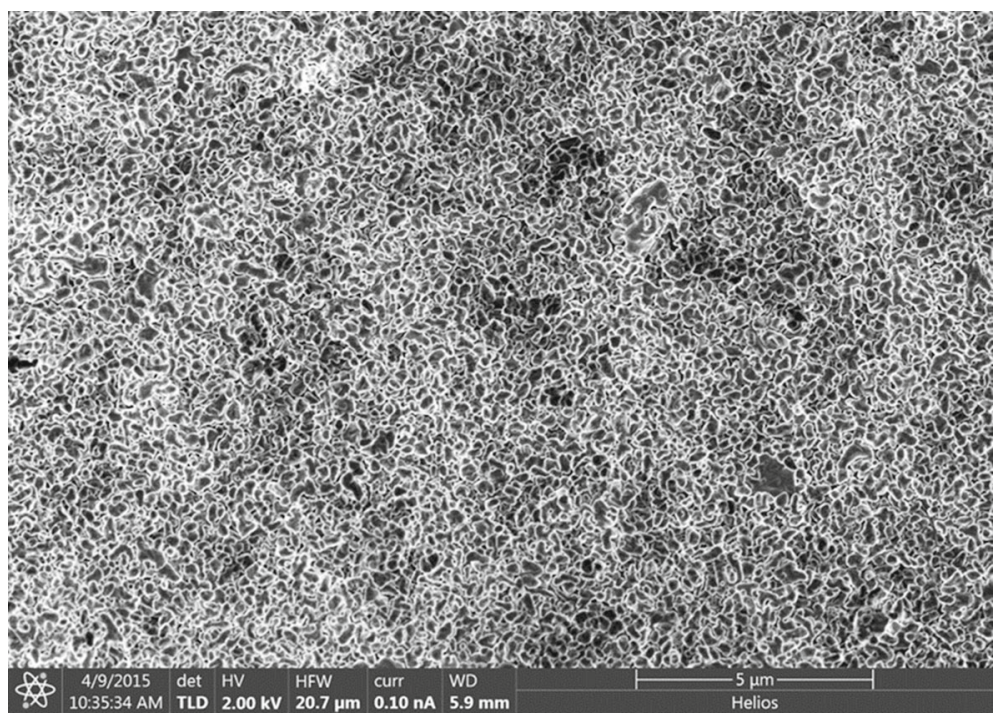

Fig. 5 SEM image of the ceramic A unpolished surface prior to site preparation for FIB-SEM imaging

the surface was a relatively flat plane perpendicular to the electron beam. Ceramic A appeared to be homogeneous, as expected from the covariance analysis and polished sample imaging, and thus the area selected for 3D analysis was chosen at random from the regions meeting the above criteria. The surface scans for the fractured ceramic B surface also appeared largely homogeneous as the imperfections as seen in the polished sample surface were hard to distinguish from the roughness of the fractured sample surface. A FIB-SEM collection site was then determined in an area free from large variations in surface roughness and other artefacts.

Serial imaging was then performed on the excavated column in a manner similar to previous studies (Holzer et al. 2004; Holzer and Cantoni 2011). The FIB-SEM imaging proceeded as a series of repeated steps in which a 10 -nm layer was removed from the face of the sample, followed by image acquisition with a pixel size of $5 \mathrm{~nm} \times 5 \mathrm{~nm}$. After completion, the image slices were aligned and trimmed to the final volume to remove any exterior artefacts. The volume cropped from the image of the ceramic A sample was $7.30 \mu \mathrm{m} \times 6.79 \mu \mathrm{m} \times 5.30 \mu \mathrm{m}$, and the corresponding volume of the ceramic B sample was $5.66 \mu \mathrm{m} \times 6.76 \mu \mathrm{m} \times 6.69 \mu \mathrm{m}$. The artefacts removed with this cropping were caused by the slight upward shift of the imaged face region and the encroachment of milled material from the side channels. The final voxel size of the registered images was $5 \mathrm{~nm} \times 6.35 \mathrm{~nm} \times 10 \mathrm{~nm}$, with the stretch in the $y$-axis voxel length being due to the orientation of the face of the sample compared to the detector of the SEM. A raw SEM image including artefacts before cropping from near the end of the imaging sequence can be seen in Fig. 6. All image processing was completed using the Avizo 9 software (FEI VSG, www.avizo3d.com) and Fiji (Schindelin et al. 2012, 2015) image viewing and processing programs.

\subsection{Image Processing and Segmentation}

Following alignment and cropping, a non-local means filter was applied to the image stacks using Avizo image processing software to reduce image noise and eliminate the streaking caused by slight charge effects on the material (Buades et al. 2005). The images from the 


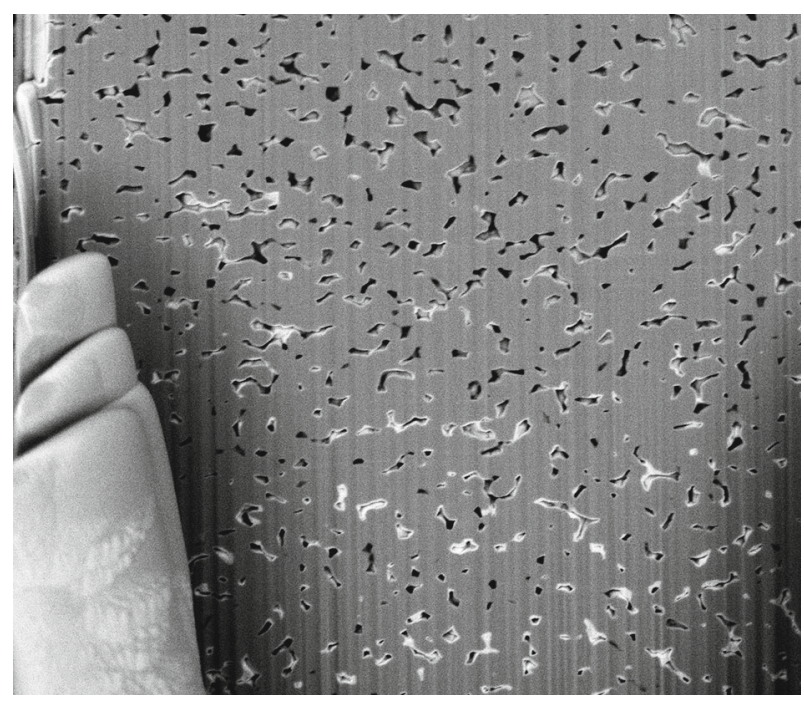

Fig. 6 Raw SEM image from face of milled column towards the end of the image collection sequence. Interference is noticeable with the intrusion of the remnants of the milled surface on the left of the image, as well as shadowing caused by the milled material

ceramic A sample also exhibited a linear change in the mean grey value intensity in the $y$-axis direction of the SEM images caused by shadowing effects from the oblique imaging angle and subsidence of the image plane into the milled trench (Keller et al. 2013b), as well a mean grey value shift along the depth of the image stack which may have been caused by changes in any of the automation steps involved in correcting each image slice in the recorded volume (Holzer et al. 2004). The linear changes in greyscale value were determined by measuring the greyscale values using a line plot along the $y$-axis and $z$-axis in the centre of the imaged volume. Figure 7 shows the line plot along the $y$-axis along with the linear fit.

The linear function from each dataset was then used to normalize the grey scale of each image slice, resulting in improved image segmentation. The linear correction for each axis was applied using the arithmetic module of Avizo. A similar approach with additional functionality for greater order polynomial fits is also provided in the background removal tool developed by Münch in the Xlib plugin set (Münch 2015) for Fiji imaging software (Schindelin et al. 2012, 2015).

An initial segmentation was performed considering only the lowest of greyscale values to be the void space within each imaged volume. This segmentation was performed by manually selecting a threshold value based on visual inspection of the results to act as an initial comparison to a more advanced segmentation discussed later. The segmentation value for ceramic A was 59 and for ceramic B was 80. These segmentations were implemented as any greyscale value below this threshold point would be assigned to the void space of the sample, while any value higher would be assigned to the solid.

This approach however does not consider that since no sample impregnation was used in the preparation of the samples, additional topological information will be recorded in each image slice from pore wall areas exposed that are below the milled plane of interest. Impregnation techniques are often employed to remove these ambiguous regions avoiding any image collection beyond the current milled surface, but was not employed in this work to provide a reference for future work on other materials where impregnation may cause 


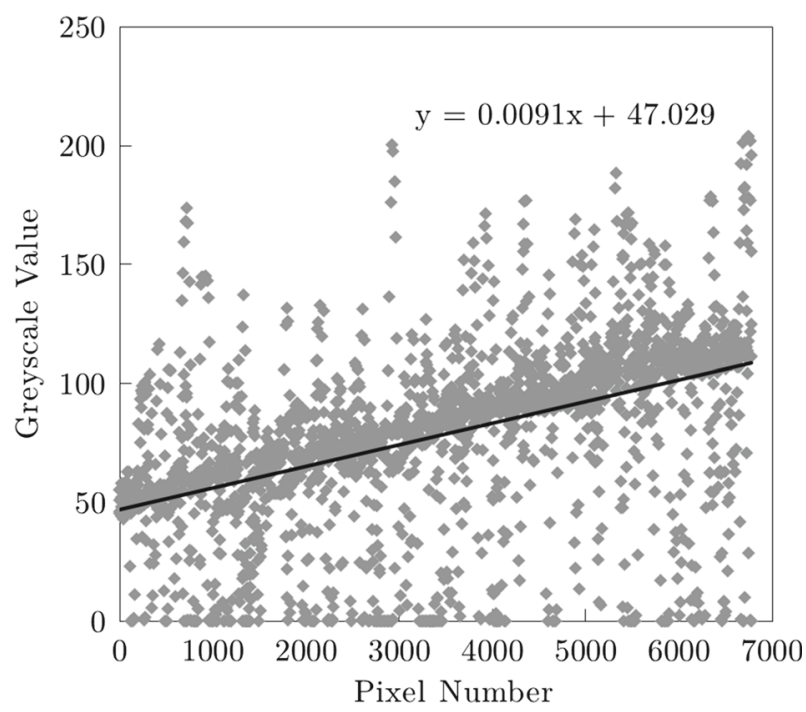

Fig. 7 Line plot of greyscale values along $y$-axis in the centre of the imaged volume along with linear fit used to adjust values for improved image segmentation

changes in sample pore space. An additional segmentation procedure was then developed to remove these image artefacts that appear as bright regions surrounding the edges of the pore-solid interface.

The pore and grains of the material were then segmented using a numerical threshold grey value range of $77-150$ for the ceramic $A$ and $72-130$ for ceramic B to select regions which were part of the milled surface of the solid that have a very uniform appearance. The value of these ranges was selected from user judgement comparing the segmentation results to the original image as the wall artefacts of the curved particle surface caused issues in quantitative approaches to selecting threshold values used in other studies (Wong et al. 2006). A more advanced watershed-based segmentation technique provided in Avizo was also attempted, but the lack of a gradient in the grey values of the edges of the curved grain surfaces and the milled face material prevented an adequate segmentation. The results of this segmentation can be seen in Fig. 8, where the remaining artefacts due to the curved interior surfaces of the pores below the plane of the slice are evident.

A closing algorithm was then used to fill in the speckling within the solid areas due to noise in the image using the closing module in Avizo applied to each $x-y$ slice with a magnitude of 1 pixel. This algorithm dilates the image followed by an erosion of the same magnitude useful in filling small holes (Chen and Haralick 1995). Next the opening module was applied using a 3-pixel-diameter disc on each $x-y$ plane to remove the pore wall "bridged" artefact areas caused by the grain curvature. The module applies an algorithm similar to the closing module where an erosion is applied to the image followed by dilation to remove small connecting elements (Chen and Haralick 1995). A 3-pixel-diameter disc was selected for use to preserve the curved surfaces surrounding each of the sample pores and at a size large enough to remove the bridge artefacts without altering other small solid features. A slice of the final segmented 3D image dataset for each ceramic can be seen in Figs. 9 and 10. It should be noted that the procedure outlined above for removing the image artefacts due to the pore walls visible below the plane of interest would be more difficult for natural rocks as the milled surface greyscale value would vary with mineral composition. 

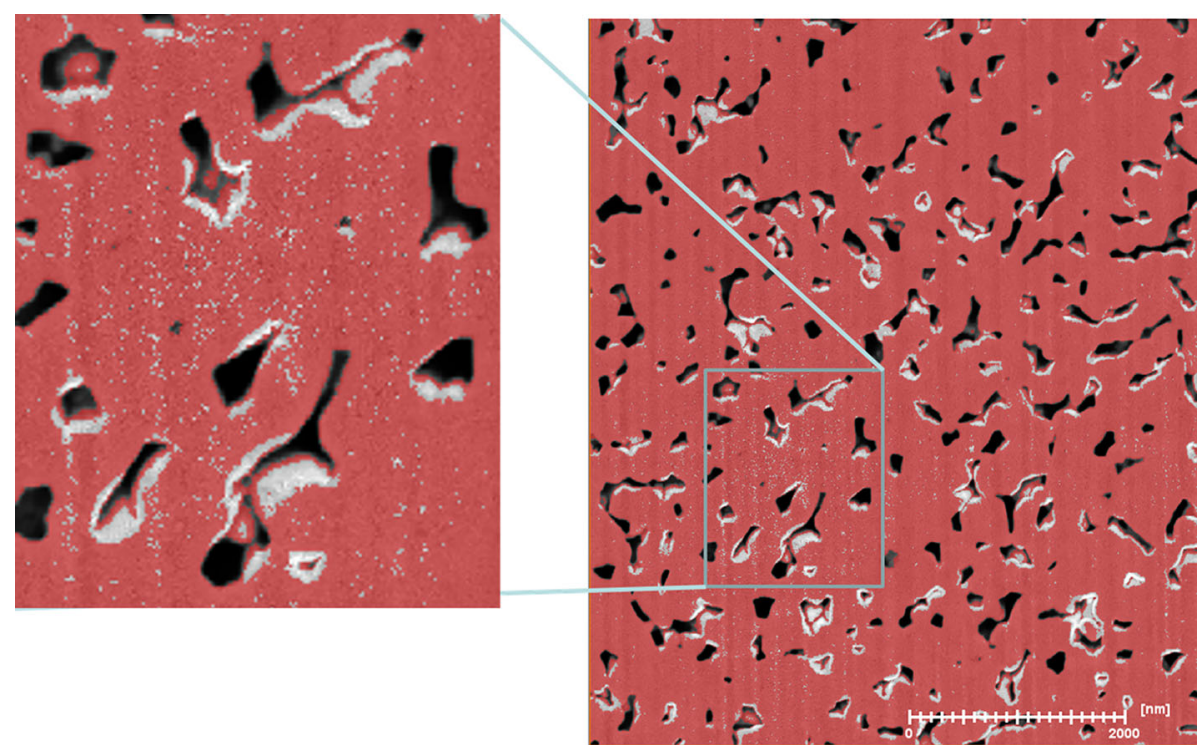

Fig. 8 Initial segmentation of pores from solid grains of ceramic B porous ceramic following filtering of image set overlaid on a $x-y$ orthogonal slice of the collected volume. Pull-out section shows the small speckled regions within solid grains caused by image noise, as well as incorrectly "bridged" segmented regions around curved grain edges

Fig. 9 Final segmentation of solid regions from pore space of the ceramic B sample following opening and closing algorithms. Regions shaded magenta were assigned to the solid phase for all subsequent calculations

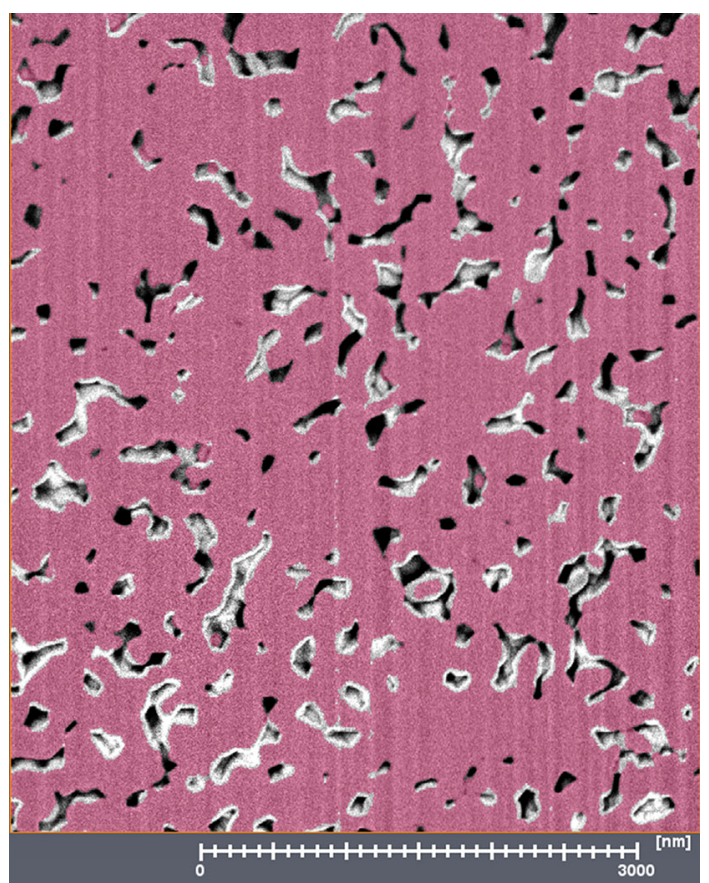




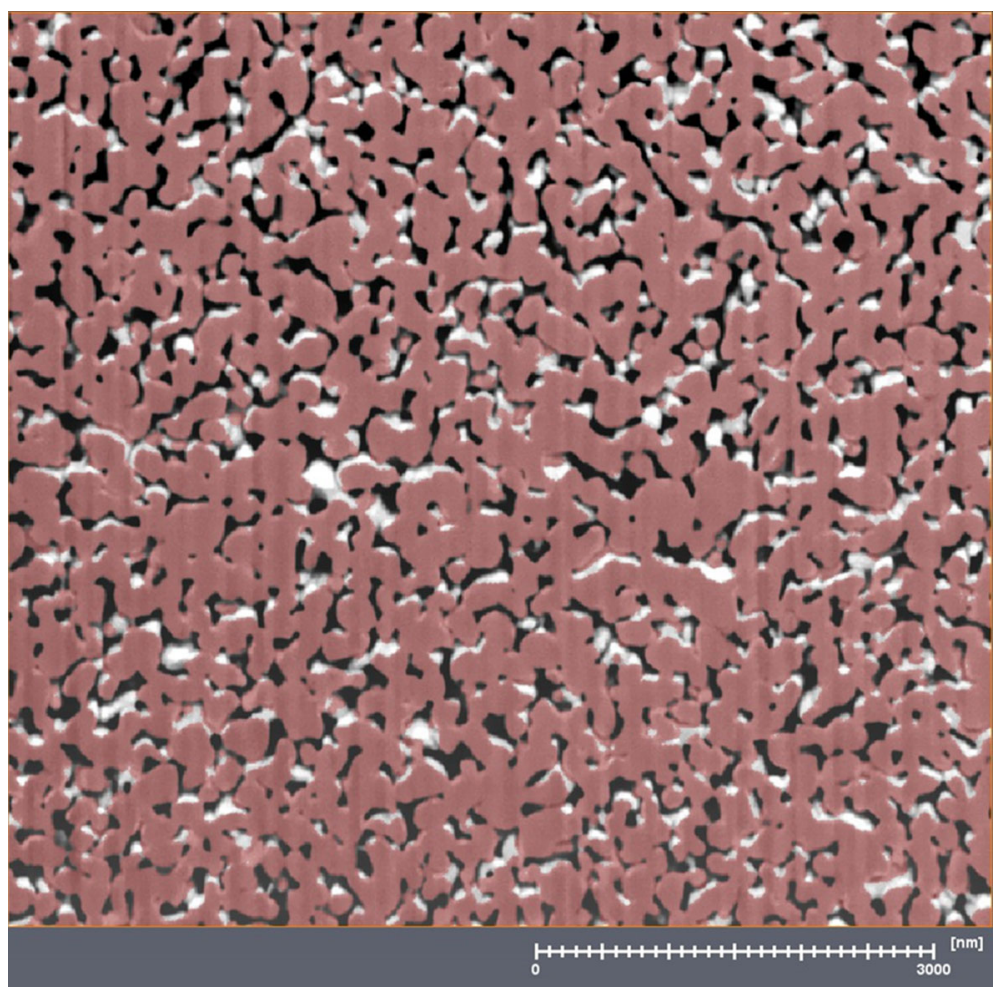

Fig. 10 Final segmentation of solid regions from pore space of the ceramic A sample following opening and closing algorithms. Regions shaded red were assigned to the solid phase for all subsequent calculations

A comparison between these two segmentations can be seen in Fig. 11 where the pore space from the initial image thresholding with the high greyscale pore wall artefacts considered to be solid shown in red, and the additional pore space added by removing the pore wall artefacts shown in blue.

\subsection{High-Pressure Mercury Intrusion}

Mercury intrusion porosimetry (MIP) measurements were taken on both of the ceramic samples provided using a Micromeritics AutoPore IV 9500. The samples used in these measurements were larger fragments collected from the remnants of the ceramic discs following plug drilling. The fragments were reduced small pieces of approximately $3 \mathrm{~mm}$ in diameter to fit within the geometry of the penetrometer available. An advancing contact angle of $130^{\circ}$ was used in the calculations.

\subsection{Single-Phase Fluid Flow Measurements}

Fluid flow measurements on both ceramic plugs samples were taken using a hydrostatic core holder apparatus connected to a twin-barrelled Quizix Q-5000 high-precision piston pump. The Q-5000 is capable of measuring flow rates down to $18 \mathrm{nl} / \mathrm{min}$ and is well suited to measure micro- to nano-Darcy sample permeabilities. A diagram of the fluid flow apparatus is shown in Fig. 12. 
Fig. 11 Example region showing difference between the two different segmentation methods. The pore space including the pore wall high greyscale value artefacts as solid shown in red, with the additional pore space generated from removing the pore wall artefacts shown in blue
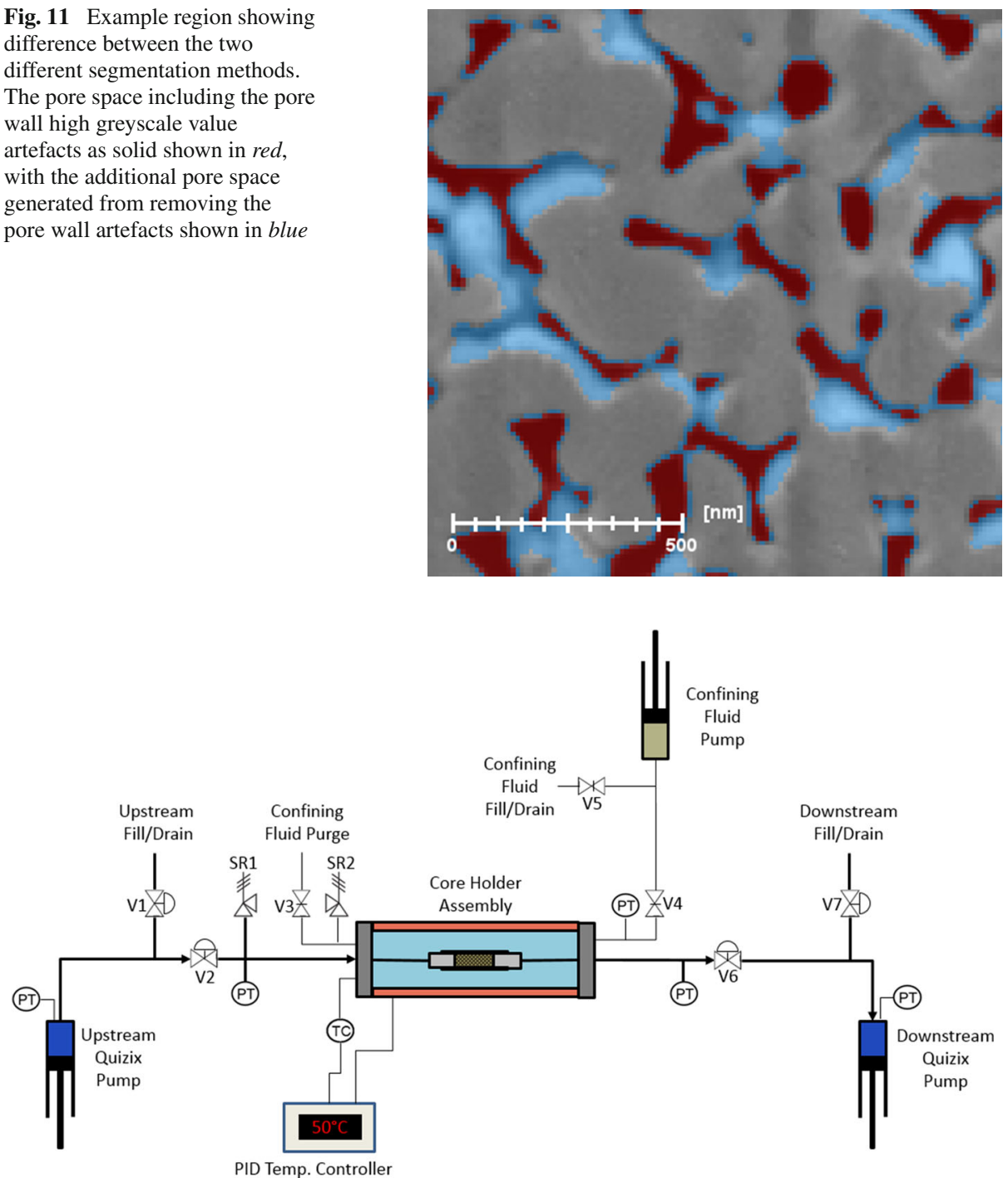

Fig. 12 Diagram of the fluid flow apparatus used in measuring plug sample permeability

The plug samples were submerged in deionized water and placed under vacuum overnight. The mass of the saturated plugs was recorded, and they were then individually loaded into Viton sleeves to isolate the sample from the confining fluid of the core holder. Tinned copper wire was used to secure the ends of the Viton sleeve to stainless steel fluid inlets. The fluid inlets had fluid dispersion channels engraved in the contact face of the plug sample for full distribution of fluid across the entire plug face. The core holder was maintained at $50^{\circ} \mathrm{C}$ using a external electric heater. PEEK tubing $1.6 \mathrm{~mm}$ in diameter was used for all fluid transport lines, with the exception of Hastelloy tubing provided on the Q-5000 pump.

A confining pressure was applied using an ISCO syringe pump operated in constant pressure mode. The Quizix pump was filled with DI-water and opened to the fluid flow lines of 
the plug sample. A confining pressure of up to $7 \mathrm{MPa}$ over the expected upstream fluid pressure was first applied to the sample; then, the pore fluid pressure of the upstream and downstream pumps was raised to a constant pressure drop across the plug sample operating the Quizix pump in constant pressure mode. Upstream and downstream pore pressures varied for each permeability measurement due to later experiment considerations not included in this work, but were always maintained above $2 \mathrm{MPa}$ with a pressure drop greater than $0.4 \mathrm{MPa}$ for each measurement. Permeability measurements were taken on both 6- and $12.5-\mathrm{mm}$ plug samples under constant pressure drop conditions, measuring the fluid displacement rates with the Quizix pump. Permeability measurements could often be determined within 30 min from the high volume resolution of the Quizix pump and relatively high sample permeability compared to similar geologic samples with nanometre-scale pores. This permeability measurement time frame would scale linearly with changes in permeability with the proportionate change in sample flow rate.

\subsection{Numerical Flow Simulations}

Fluid flow simulations were performed on the segmented pore space images using the latticeBoltzmann (LB) method. In this model, a discrete form of the Boltzmann scheme is solved on a Cartesian grid and can be shown to reduce to the incompressible Navier-Stokes equations (He and Luo 1997). The LB method has been applied extensively to problems in porous media flows (Sukop and Thorne 2007; Boek and Venturoli 2010; Shah et al. 2015; Yoon et al. 2015) due to its computational efficiency and simplicity. The central variable is the distribution function $f_{i}(\boldsymbol{x}, t)$ which represents the number of fluid particles at a grid position $\boldsymbol{x}$, at time $t$ having a velocity which is one of a discrete set indexed by $i$. The local hydrodynamic variables density $\rho(\boldsymbol{x}, t)$ and velocity $\boldsymbol{u}(\boldsymbol{x}, t)$ are then computed from the relations:

$$
\rho(\boldsymbol{x}, t)=\sum_{i} f_{i} \quad \boldsymbol{u}(\boldsymbol{x}, t)=\frac{1}{\rho} \sum_{i} \boldsymbol{e}_{i} f_{i}+\frac{\boldsymbol{g}}{2}
$$

where $\boldsymbol{g}$ is a body-force acting on the fluid, and $\boldsymbol{e}_{i}$ is velocity $i$ from the D3Q19 lattice scheme (Qian et al. 1992) in which the definition for velocity is according to the forcing scheme of Guo and Zheng (2008), where $\boldsymbol{g}$ is a body-force, and $\boldsymbol{e}_{i}$ is the $i$ th of the 19 velocity vectors at each lattice site which are defined as:

$$
\boldsymbol{e}=\left[\begin{array}{ccccccccccccccccccc}
0 & 1 & -1 & 0 & 0 & 0 & 0 & 1 & -1 & 1 & -1 & 0 & 0 & 0 & 0 & 1 & -1 & 1 & -1 \\
0 & 0 & 0 & 1 & -1 & 0 & 0 & 1 & 1 & -1 & -1 & 1 & -1 & 1 & -1 & 0 & 0 & 0 & 0 \\
0 & 0 & 0 & 0 & 0 & 1 & -1 & 0 & 0 & 0 & 0 & 1 & 1 & -1 & -1 & 1 & 1 & -1 & -1
\end{array}\right]^{T}
$$

The fluid equations are solved by iterating the discretized Boltzmann equation which consists of two operations: (1) particle collisions which relax the distribution function to an equilibrium state and (2) particle streaming in which particle populations are convected to neighbouring grid nodes.

$$
f_{i}\left(\boldsymbol{x}+\boldsymbol{e}_{i} d t, t+d t\right)=f_{i}(\boldsymbol{x}, t)+\Omega_{i}[\boldsymbol{f}(\boldsymbol{x}, t)]
$$

Here, $d t=1$ is the time step and $\Omega_{i}$ is the particle collision operator. We use here the multiple-relaxation-time (MRT) collision model with a fluid body-force (Gray and Boek 2016). Then the collision operator $\Omega_{i}$ is then specified by Guo and Zheng (2008):

$$
\Omega_{i}[\boldsymbol{f}(\boldsymbol{x}, t)]=\boldsymbol{M}_{i}^{-1}\left[\boldsymbol{S M}\left(\boldsymbol{f}^{E q}-\boldsymbol{f}\right)+\left(\boldsymbol{I}-\frac{1}{2} \boldsymbol{S}\right) \boldsymbol{M F}\right]
$$


Here, the matrix $\boldsymbol{M}$ transforms the non-equilibrium part of the distribution function to a moment space, the diagonal matrix $\boldsymbol{S}$ specifies individual relaxation rates for each moment, and the inverse matrix $\boldsymbol{M}^{-1}$ restores the distribution vector to velocity space for streaming (d'Humières 2002). $\boldsymbol{I}$ is the identity matrix, and $\boldsymbol{F}$ is the force term. We use here the two relaxation time formulations in which symmetric and antisymmetric moments are relaxed with different rates (Talon et al. 2012). The two relaxation rates are specified according to the recommendation of d'Humières and Ginzburg (2009) and are shown to lead to viscosityindependent non-slip boundary solutions with the bounce-back boundary method (Pan et al. 2006). The components of the equilibrium distribution function $f^{E q}(\boldsymbol{x}, t)$ are defined in terms of the local density and velocity as:

$$
\boldsymbol{f}_{i}^{E q}(\rho, \boldsymbol{u})=\rho \boldsymbol{w}_{i}\left[1+3 \boldsymbol{e}_{i} \cdot \boldsymbol{u}+\frac{9}{2}\left(\boldsymbol{e}_{i} \cdot \boldsymbol{u}\right)^{2}-\frac{3}{2} \boldsymbol{u}^{2}\right]
$$

where the lattice weights $\boldsymbol{w}_{i}$ are given in D3Q19 by $w_{0}=1 / 3, w_{1-7}=1 / 18, w_{8-18}=1 / 36$ (Qian et al. 1992). The force term is expanded to second order in velocity and is given by (Guo et al. 2002):

$$
F_{i}=3 w_{i}\left[\boldsymbol{e}_{i} \cdot \boldsymbol{g}+\boldsymbol{u g}:\left(3 \boldsymbol{e}_{i} \boldsymbol{e}_{i}-\boldsymbol{I}\right)\right]
$$

Here we compute the flow in 3D pore space images obtained from FIB-SEM imaging. The samples are reflected about the $x=0$ plane to give continuous loop boundary conditions so that a body-force may be used (Yang et al. 2013). A uniform body-force of $g=10^{-6}$ in lattice units was used, and the viscosity $v=1 / 6$. Prior to pore segmentation for fluid flow properties analysis, the FIB-SEM images were resampled to a $10 \mathrm{~nm} \times 10 \mathrm{~nm} \times 10 \mathrm{~nm}$ lattice for use with our fluid flow simulator. The image was then mirrored in the direction of desired fluid flow path, with periodic boundary conditions between the now matching faces. A constant body-force was imposed on the fluid and the calculation iterated until the velocity field showed changes of less than $10^{-6}$ of the previous iteration. There was no significant change in the calculated porosity values using the original and resampled image sets.

Permeability was then computed from Darcy's law. There was no significant change in the calculated porosity values using the original and resampled image sets.

\section{Results and Discussion}

The results from the high-pressure mercury intrusion experiments, Figs. 13 and 14, show some very large pore entry radii $(>50 \mu \mathrm{m})$, which are thought to be due to fractures within the sample induced while breaking it into smaller fragments. These large pore entry radii sizes can also be the result of contact points between different sample pieces, but were not found to be present in any of the sample imaging. The mercury intrusion results for ceramic $\mathrm{B}$ also show a small peak located at a pore entry radius of $5 \mu \mathrm{m}$ consistent with the small imperfections observed in the polished SEM surface images.

The total porosity of the samples was determined gravimetrically by weighing the samples before and after saturating with water. This is reported in Table 1 as an average of repeat measurements together with the standard deviation for each sample. The porosity was also determined from the FIB-SEM images and is reported in Table 1. The segmented porosity from the initial thresholding (red segmented pore space in Fig. 11) of only the darkest greyscale values appears to be significantly lower than the measured values for each sample; however, after elimination of the high greyscale artefacts from the image segmentation (blue segmented pore space in Fig. 11) we see a reasonable agreement between the segmented FIB- 


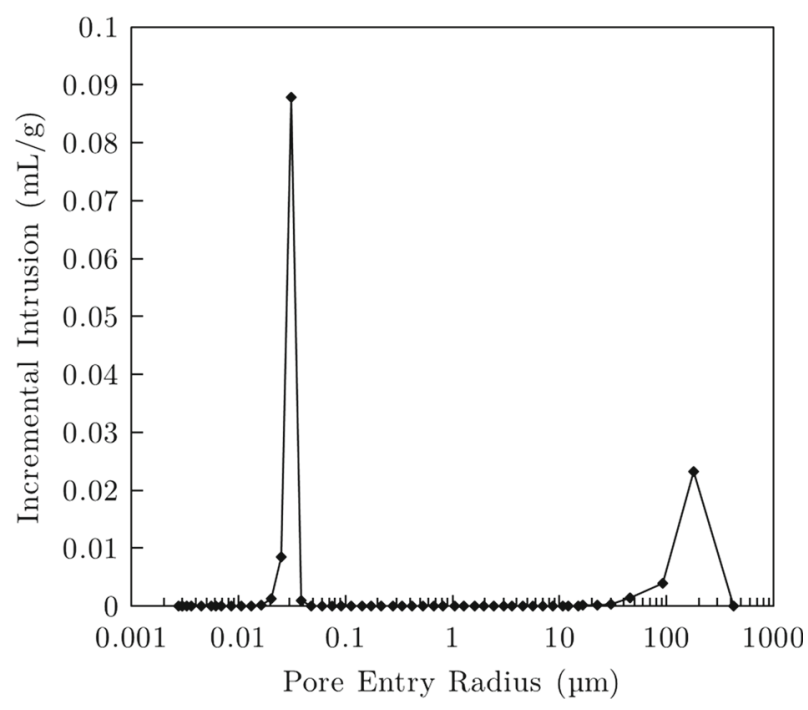

Fig. 13 High-pressure mercury incremental intrusion for ceramic A

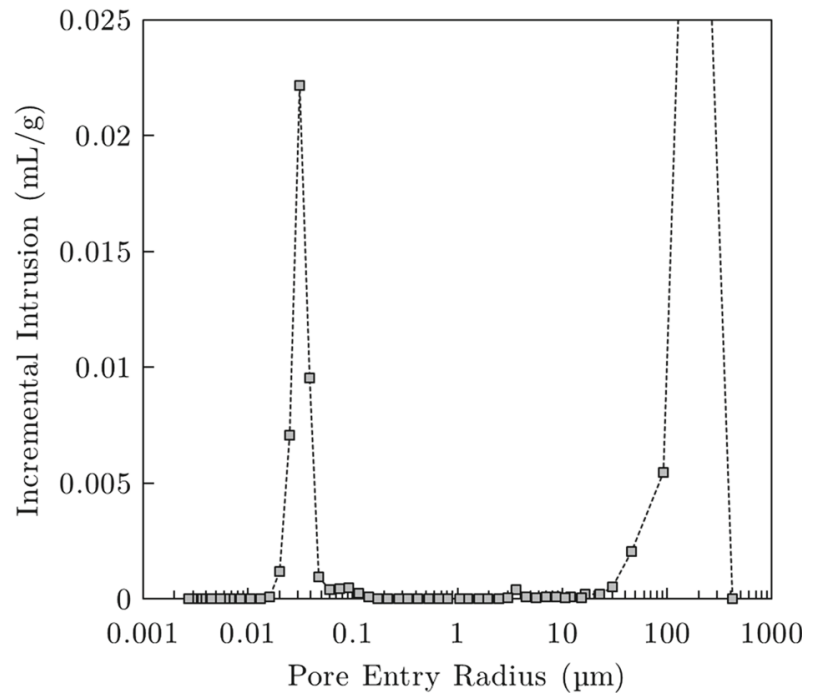

Fig. 14 High-pressure mercury incremental intrusion for ceramic B

SEM images and gravimetrically determined sample porosity. Given the huge difference in the measurement volume between the images and the gravimetric analysis, this reinforces the homogeneity of the bulk of the samples pore space. However, the small discrepancy beyond the repeatability of the gravimetric measurements could be caused by variation in the image segmentation criteria relying on user judgement rather than a quantitative assessment.

The three-dimensional continuous pore size distribution (3DCPSD) and mercury intrusion simulation results were then produced for each ceramic sample from the segmented pore space using the algorithm as developed by Münch and Holzer (Münch and Holzer 2008; Münch 2015). Comparisons between the 3DCPSD, mercury intrusion simulation, and the mercury 
Table 1 Comparison of porosity estimates

\begin{tabular}{llll}
\hline Sample & $\begin{array}{l}\text { Segmented pores [initial] } \\
\text { from FIB-SEM porosity } \\
(\%)\end{array}$ & $\begin{array}{l}\text { Segmented pores [w/artefact } \\
\text { elimination] from FIB-SEM } \\
\text { porosity }(\%)\end{array}$ & $\begin{array}{l}\text { Gravimetrically } \\
\text { calculated porosity } \\
(\%)\end{array}$ \\
\hline Ceramic A & 12.73 & 26.9 & $28.3 \pm 0.3$ \\
Ceramic B & 6.57 & 16.5 & $15.2 \pm 0.5$ \\
\hline
\end{tabular}

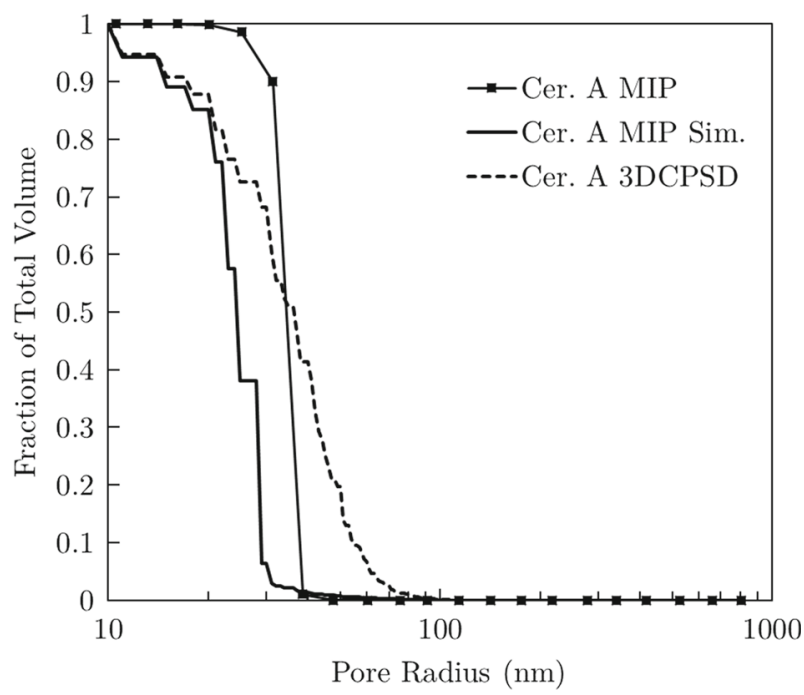

Fig. 15 Calculated continuous pore size distribution and MIP simulation results for ceramic A as compared to measured mercury intrusion porosimetry results

intrusion results normalized for pore throat radii below $1 \mu \mathrm{m}$ is shown in Figs. 15 and 16. The mercury intrusion results are only shown in comparison with the pore sizes relevant to the analysis of the FIB-SEM imaged volumes.

These comparisons of the 3DCPSD results, the MIP simulation, and the MIP experimental results show a good agreement providing further evidence that the FIB-SEM extracted 3D volumes were representative of the whole samples. The slight deviation in the tail of the pore radii towards larger pore sizes is the result of comparing the 3DCPSD algorithm which has full access to the entire sample pore space in allocating larger pore radii, whereas mercury intrusion is restricted in having to pass through smaller pore throats before gaining access to larger pore bodies. This limitation then also gives rise to the narrowing of smaller pore radii intrusion as larger pore spaces are attributed to the pore entry radii at which the mercury gains access to the larger pores. The MIP simulation then provides results that have a very similar form to those of the MIP experiments, albeit restricted within the previously observed 3DCPSD model. This shows a good performance of the MIP simulation in comparison with the experiment results as the narrower pore throats prior to access to larger pore bodies are then accounted for in the model.

Deviations in the 3DCPSD and MIP simulations results for the smaller pore radii are likely to be affected by the artificial roughness introduced in the transforming of the real sample pore space into a voxelized volume. The deviation of the MIP simulation results and 


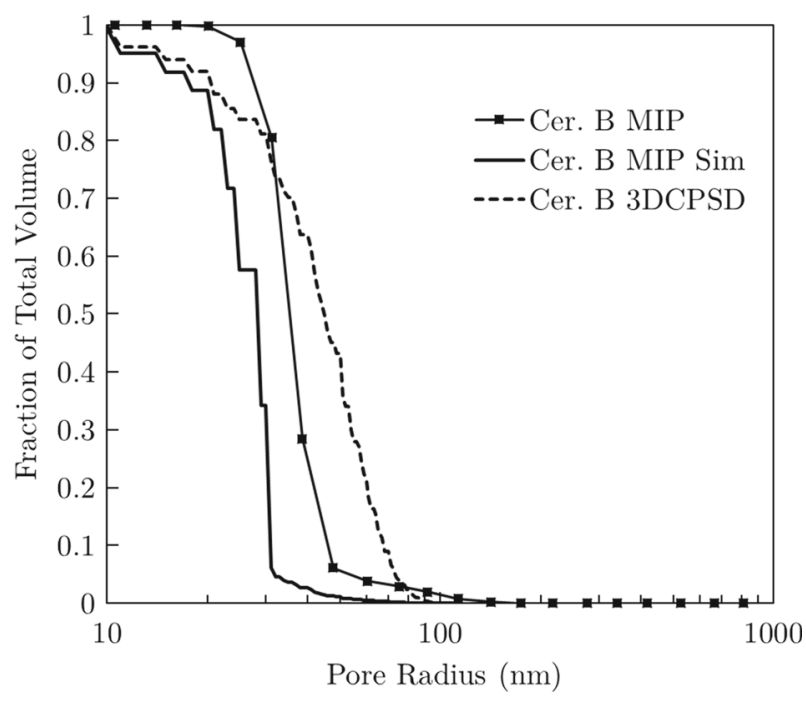

Fig. 16 Calculated continuous pore size distribution and MIP simulation results for ceramic B as compared to measured mercury intrusion porosimetry results

that of the MIP experiments can also be remedied in varying the advancing contact angle selected in the analysis of the MIP experiment results. A value of $130^{\circ}$ was selected under the recommendation of the service provider for the MIP instrument in agreement with the work of Good and Mikhail (1981), but other works have also commonly used $\sim 140^{\circ}$ with geologic samples (Hildenbrand et al. 2002; Carles et al. 2010).

An example of the fluid flow field resulting from the LB simulation is given in Fig. 17 and the simulation permeability for both samples with and without artefact removal is shown in Table 2. The results of multiple experimental permeability measurements are also show in Table 2. The error presented for the experimental values is the standard deviation of the repeat measurements. The error for the numerically derived permeability is given as the standard deviation of the anisotropy of permeability along the $x$-, $y$ - and $z$ - axis of the FIB-SEM segmented image.

These results show the significant impact that the imaging artefacts have on the numerically determined permeability of the sample. It is possible to begin to accurately predict the sample permeability only after eliminating the high greyscale artefacts from the pore walls. The experimental and simulated permeability for ceramic A agrees to within the repeatability of the experimental values on plugs taken from different regions of the original large sample. There is a small discrepancy beyond the experimental repeatability between the simulation and the experiment for the ceramic B sample and may be the result of some of the larger-scale heterogeneities found within the sample unaccounted for in the FIB-SEM reconstruction. These results give confidence in the use of this technique for the accurate prediction of the permeability of nanometre-scale porous regions.

\section{Conclusions}

FIB-SEM imaging was used to obtain detailed images of two nanometre-scale homogeneous porous ceramics. An image artefact was observed near the void-solid interface for many of the 


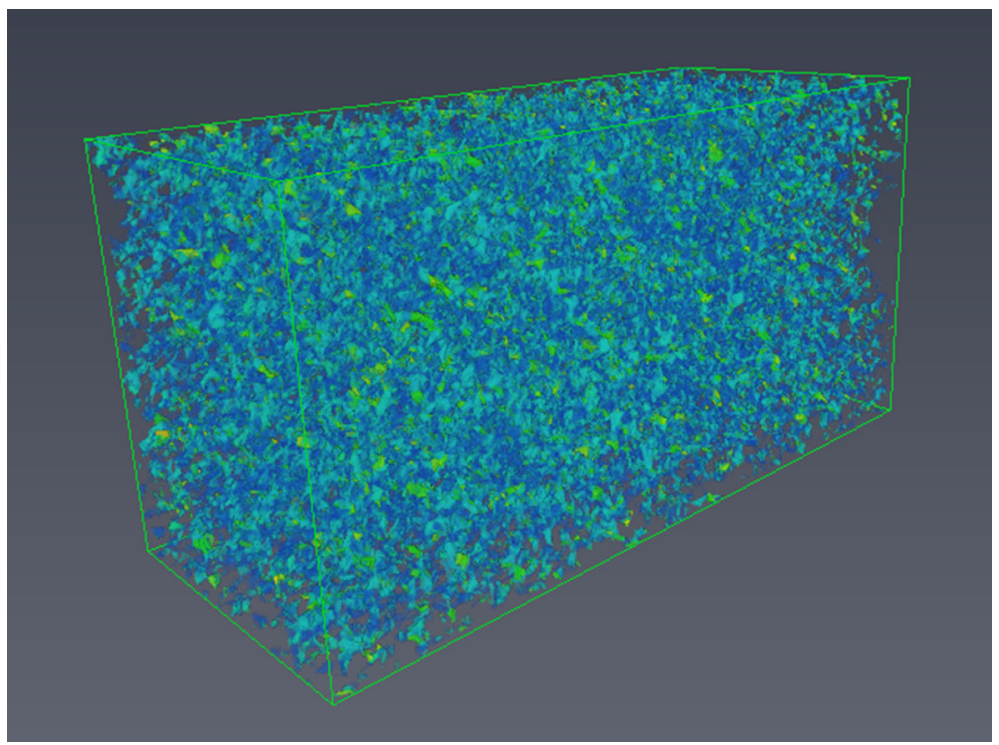

Fig. 17 Volume rendering of fluid velocity magnitudes calculated for the ceramic B sample from the results of the lattice-Boltzmann flow simulation in the $z$-axis (left face to right face, slightly into page). The blue colours represent slower velocities, and higher velocities are shown in green then yellow. The overall size of this simulated volume is $5.66 \mu \mathrm{m} \times 6.76 \mu \mathrm{m} \times 13.38 \mu \mathrm{m}$

Table 2 Comparison of experimental measurements of plug permeability and lattice-Boltzmann calculated single-phase permeability

\begin{tabular}{llllc}
\hline Sample & $\begin{array}{l}\text { No. of } \\
\text { experimental } \\
\text { measurements }\end{array}$ & $\begin{array}{l}\text { Measured } \\
\text { permeability } \\
(\mu \text { Darcy })\end{array}$ & $\begin{array}{l}\text { LB determined } \\
\text { permeability } \\
{[\text { initial] }(\mu \text { Darcy })}\end{array}$ & $\begin{array}{l}\text { LB determined } \\
\text { permeability [w/artefact } \\
\text { elimination] }(\mu \text { Darcy })\end{array}$ \\
\hline Ceramic A & 12 & $16.0 \pm 4.4$ & $1.5 \pm 0.8$ & $14.5 \pm 0.8$ \\
Ceramic B & 9 & $7.9 \pm 0.2$ & $0.2 \pm 0.1$ & $5.6 \pm 0.3$ \\
\hline
\end{tabular}

pore walls due to secondary electrons from the curved grain surface below the milled plane of reference. Two separate image segmentations were performed considering this wall artefact either solid or void space in each of the FIB-SEM image slices. The segmented porosity of each ceramic sample in which the pore wall imaging artefacts were considered to be void space provided the best match to the sample gravimetric porosity. Subsequently, latticeBoltzmann numerical flow simulation was shown to accurately predict the permeability of the samples by comparison with experimental permeability measurements on plug sample over a billion times the volume of the FIB-SEM image volume. This directly validates permeability estimations performed on extracted FIB-SEM imaged pore spaces at the scale of 10-100 nm for the first time. The accuracy of these permeability estimates depends on numerous factors including the accurate segmentation of pore space images and the representativeness of the extracted volume; however, this work supports continued work in the digital rock approach for natural rocks with very small pores. A understanding of the effects of multiscale pore space heterogeneity and pore space connectivity that may be more difficult to obtain in natural systems remains to be established. 
Acknowledgements The authors would like to acknowledge the support of the Qatar Carbonates and Carbon Storage Research Centre (QCCSRC) for the funding of this project, specifically Imperial College London, Shell, Qatar Petroleum and Qatar Science and Technology Park for their contribution to this scientific effort. The authors would also like to thank the FEI Company for their assistance and cooperation in collecting the imaging work essential for this publication.

Open Access This article is distributed under the terms of the Creative Commons Attribution 4.0 International License (http://creativecommons.org/licenses/by/4.0/), which permits unrestricted use, distribution, and reproduction in any medium, provided you give appropriate credit to the original author(s) and the source, provide a link to the Creative Commons license, and indicate if changes were made.

\section{References}

Amann-Hildenbrand, A., Bertier, P., Busch, A., Krooss, B.M.: Experimental investigation of the sealing capacity of generic clay-rich caprocks. Int. J. Greenh. Gas Control 19, 620-641 (2013)

Blunt, M.J., Bijeljic, B., Dong, H., Gharbi, O., Iglauer, S., Mostaghimi, P., Paluszny, A., Pentland, C.: Pore-scale imaging and modelling. Adv. Water Resour. 51, 197-216 (2013)

Boek, E.S., Venturoli, M.: Lattice-Boltzmann studies of fluid flow in porous media with realistic rock geometries. Comput. Math. Appl. 59(7), 2305-2314 (2010)

Boulin, P., Bretonnier, P., Vassil, V., Samouillet, A., Fleury, M., Lombard, J.: Entry pressure measurements using three unconventional experimental methods. In: International Symposium of the Society of Core Analysts (2011)

Boulin, P., Bretonnier, P., Gland, N., Lombard, J.M.: Contribution of the steady state method to water permeability measurement in very low permeability porous media. Oil Gas Sci. Technol. Rev. d'IFP Energ. N. 67(3), 387-401 (2012)

Boulin, P., Bretonnier, P., Vassil, V., Samouillet, A., Fleury, M., Lombard, J.: Sealing efficiency of caprocks: experimental investigation of entry pressure measurement methods. Mar. Pet. Geol. 48, 20-30 (2013)

Brace, W.F., Walsh, J.B., Frangos, W.T.: Permeability of granite under high pressure. J. Geophys. Res. 73(6), 2225 (1968)

Buades, A., Coll, B., Morel, J.M.: A non-local algorithm for image denoising. In: Computer Vision and Pattern Recognition. IEEE Computer Society Conference on IEEE CVPR 2005, vol. 2, pp. 60-65 (2005)

Cantrell, D.L., Hagerty, R.M.: Microporosity in arab formation carbonates, Saudi Arabia. GeoArabia 4(2), 129-154 (1999)

Carles, P., Bachaud, P., Lasseur, E., Berne, P., Bretonnier, P.: Confining properties of carbonated dogger caprocks (parisian basin) for $\mathrm{CO}_{2}$ storage purpose. Oil Gas Sci. Technol. Rev. Inst. Fr. Pet. 65(3), 461-472 (2010)

Chen, S., Haralick, R.M.: Recursive erosion, dilation, opening, and closing transforms. IEEE Trans. Image Process. 4(3), 335-345 (1995)

Cui, X., Bustin, A., Bustin, R.M.: Measurements of gas permeability and diffusivity of tight reservoir rocks: different approaches and their applications. Geofluids 9(3), 208-223 (2009)

Desbois, G., Urai, J., Houben, M., Sholokhova, Y.: Typology, morphology and connectivity of pore space in claystones from reference site for research using bib, fib and cryo-sem methods. In: EPJ Web of Conferences, EDP Sciences, vol. 6, p. 22005 (2010)

Desbois, G., Urai, J.L., Kukla, P.A., Konstanty, J., Baerle, C.: High-resolution 3d fabric and porosity model in a tight gas sandstone reservoir: a new approach to investigate microstructures from mm-to nm-scale combining argon beam cross-sectioning and sem imaging. J. Pet. Sci. Eng. 78(2), 243-257 (2011)

d'Humières, D.: Multiple-relaxation-time lattice boltzmann models in three dimensions. Philos. Trans. R. Soc. Lond. A Math. Phys. Eng. Sci. 360(1792), 437-451 (2002). doi:10.1098/rsta.2001.0955

d'Humières, D., Ginzburg, I.: Viscosity independent numerical errors for lattice boltzmann models: from recurrence equations to magic collision numbers. Comput. Math. Appl. 58(5), 823-840 (2009)

Good, R.J., Mikhail, R.S.: The contact angle in mercury intrusion porosimetry. Powder Technol. 29(1), 53-62 (1981)

Gray, F., Boek, E.: Enhancing computational precision for lattice Boltzmann schemes in porous media flows. Computation 4(1), 11 (2016)

Groeber, M., Haley, B., Uchic, M., Dimiduk, D., Ghosh, S.: 3d reconstruction and characterization of polycrystalline microstructures using a fib-sem system. Mater. Charact. 57(4), 259-273 (2006)

Guo, Z., Zheng, C.: Analysis of lattice Boltzmann equation for microscale gas flows: relaxation times, boundary conditions and the knudsen layer. Int. J. Comput. Fluid Dyn. 22(7), 465-473 (2008) 
Guo, Z., Zheng, C., Shi, B.: Discrete lattice effects on the forcing term in the lattice Boltzmann method. Phys. Rev. E 65(4), 046308 (2002)

Harrington, J.F., Horseman, S.T.: Gas transport properties of clays and mudrocks. Geol. Soc. Lond. Spec. Publ. 158(1), 107-124 (1999)

He, X., Luo, L.S.: Theory of the lattice Boltzmann method: from the boltzmann equation to the lattice Boltzmann equation. Phys. Rev. E 56(6), 6811 (1997)

Hemes, S., Desbois, G., Urai, J.L., Schrppel, B., Schwarz, J.O.: Multi-scale characterization of porosity in boom clay (hades-level, mol, belgium) using a combination of X-ray -ct, 2d bib-sem and fib-sem tomography. Microporous Mesoporous Mater. 208, 1-20 (2015)

Hildenbrand, A., Schlomer, S., Krooss, B.: Gas breakthrough experiments on fine grained sedimentary rocks. Geofluids 2(1), 3-23 (2002)

Hildenbrand, A., Schlomer, S., Krooss, B., Littke, R.: Gas breakthrough experiments on pelitic rocks: comparative study with N2, CO2 and CH4. Geofluids 4(1), 61-80 (2004)

Holzer, L., Cantoni. M.: Review of fib-tomography. In: Nanofabrication Using Focused Ion and Electron Beams: Principles and Applications. Oxford University Press, Oxford. ISBN 559201222 (2011)

Holzer, L., Indutnyi, F., Gasser, P., Münch, B., Wegmann, M.: Three-dimensional analysis of porous batio3 ceramics using fib nanotomography. J. Microsc. 216(1), 84-95 (2004)

Holzer, L., Muench, B., Wegmann, M., Gasser, P., Flatt, R.J.: Fib-nanotomography of particulate systems part i: particle shape and topology of interfaces. J. Am. Ceram. Soc. 89(8), 2577-2585 (2006)

Hsieh, P., Tracy, J., Neuzil, C., Bredehoeft, J., Silliman, S.: A transient laboratory method for determining the hydraulic properties of 'tight'rocksi. theory. In: International Journal of Rock Mechanics and Mining Sciences and Geomechanics Abstracts, Elsevier, vol. 18, pp. 245-252 (1981)

Javadpour, F., Fisher, D., Unsworth, M.: Nanoscale gas flow in shale gas sediments. J. Can. Pet. Technol. 46(10), 55-61 (2007)

Keller, L.M., Holzer, L., Schuetz, P., Gasser, P.: Pore space relevant for gas permeability in opalinus clay: statistical analysis of homogeneity, percolation, and representative volume element. J. Geophys. Res. Solid Earth 118(6), 2799-2812 (2013a)

Keller, L.M., Schuetz, P., Erni, R., Rossell, M.D., Lucas, F., Gasser, P., Holzer, L.: Characterization of multiscale microstructural features in opalinus clay. Microporous Mesoporous Mater. 170, 83-94 (2013b)

Li, S., Dong, M., Li, Z., Huang, S., Qing, H., Nickel, E.: Gas breakthrough pressure for hydrocarbon reservoir seal rocks: implications for the security of long-term co2 storage in the weyburn field. Geofluids 5(4), 326-334 (2005)

Luffel, D., Hopkins, C., Schettler Jr, P., et al.: Matrix permeability measurement of gas productive shales. In: SPE Annual Technical Conference and Exhibition, Society of Petroleum Engineers (1993)

Münch B (2015) Xlib. http://imagej.net/Xlib

Münch, B., Holzer, L.: Contradicting geometrical concepts in pore size analysis attained with electron microscopy and mercury intrusion. J. Am. Ceram. Soc. 91(12), 4059-4067 (2008)

Neuzil C, Cooley C, Silliman S, Bredehoeft J, Hsieh P (1981) A transient laboratory method for determining the hydraulic properties of tightrocksii. application. In: International Journal of Rock Mechanics and Mining Sciences and Geomechanics Abstracts, Elsevier, vol. 18, pp. 253-258

Ortiz, L., Volckaert, G., Mallants, D.: Gas generation and migration in boom clay, a potential host rock formation for nuclear waste storage. Eng. Geol. 64(2), 287-296 (2002)

Pan, C., Luo, L.S., Miller, C.T.: An evaluation of lattice Boltzmann schemes for porous medium flow simulation. Comput. Fluids 35(8), 898-909 (2006)

Peng, S., Loucks, B.: Permeability measurements in mudrocks using gas-expansion methods on plug and crushed-rock samples. Mar. Pet. Geol. 73, 299-310 (2016)

Qian, Y., d'Humières, D., Lallemand, P.: Lattice BGK models for Navier-Stokes equation. EPL (Europhys. Lett.) 17(6), 479 (1992)

Sakhaee-Pour, A., Bryant, S.: Gas permeability of shale. SPE Reserv. Eval. Eng. 15(04), 401-409 (2012)

Schindelin, J., Arganda-Carreras, I., Frise, E., Kaynig, V., Longair, M., Pietzsch, T., Preibisch, S., Rueden, C., Saalfeld, S., Schmid, B., et al.: Fiji: an open-source platform for biological-image analysis. Nat. Methods 9(7), 676-682 (2012)

Schindelin, J., Rueden, C.T., Hiner, M.C., Eliceiri, K.W.: The imagej ecosystem: an open platform for biomedical image analysis. Mol. Reprod. Dev. 82(7-8), 518-529 (2015)

Schlomer, S., Krooss, B.: Experimental characterisation of the hydrocarbon sealing efficiency of cap rocks. Mar. Pet. Geol. 14(5), 565-580 (1997)

Shah, S., Gray, F., Crawshaw, J., Boek, E.: Micro-computed tomography pore-scale study of flow in porous media: effect of voxel resolution. Adv. Water Resour. 95, 276-287 (2015)

Sing, K.S.: Reporting physisorption data for gas/solid systems with special reference to the determination of surface area and porosity (recommendations 1984). Pure Appl. Chem. 57(4), 603-619 (1985) 
Song, Y., Davy, C.A., Troadec, D., Blanchenet, A.M., Skoczylas, F., Talandier, J., Robinet, J.C.: Multi-scale pore structure of cox claystone: towards the prediction of fluid transport. Mar. Pet. Geol. 65, 63-82 (2015)

Song, Y., Davy, C.A., Bertier, P., Troadec, D.: Understanding fluid transport through claystones from their 3d nanoscopic pore network. Microporous Mesoporous Mater. 228, 64-85 (2016)

Sukop, M.C., Thorne, D.T.: Lattice Boltzmann Modeling: An Introduction for Geoscientists and Engineers. Springer Science \& Business Media, Berlin (2007)

Talon, L., Bauer, D., Gland, N., Youssef, S., Auradou, H., Ginzburg, I.: Assessment of the two relaxation time lattice-boltzmann scheme to simulate stokes flow in porous media. Water Resour. Res. 48(4), W04526 (2012)

Thomas, L., Katz, D., Tek, M.: Threshold pressure phenomena in porous media. Soc. Pet. Eng. J. 8(02), 174-184 (1968)

Van Loon, L.R., Soler, J.M., Muller, W., Bradbury, M.H.: Anisotropic diffusion in layered argillaceous rocks: a case study with opalinus clay. Environ. Sci. Technol. 38(21), 5721-5728 (2004)

Wirth, R.: Focused ion beam (fib) combined with SEM and tem: advanced analytical tools for studies of chemical composition, microstructure and crystal structure in geomaterials on a nanometre scale. Chem. Geol. 261(34), 217-229 (2009)

Wollenweber, J., Sa, Alles, Kronimus, A., Busch, A., Stanjek, H., Krooss, B.M.: Caprock and overburden processes in geological CO2 storage: an experimental study on sealing efficiency and mineral alterations. Energy Proced. 1(1), 3469-3476 (2009)

Wollenweber, J., Alles, S., Busch, A., Krooss, B.M., Stanjek, H., Littke, R.: Experimental investigation of the CO2 sealing efficiency of caprocks. Int. J. Greenh. Gas Control 4(2), 231-241 (2010)

Wong, H., Head, M., Buenfeld, N.: Pore segmentation of cement-based materials from backscattered electron images. Cem. Concr. Res. 36(6), 1083-1090 (2006)

Yang, J., Crawshaw, J., Boek, E.S.: Quantitative determination of molecular propagator distributions for solute transport in homogeneous and heterogeneous porous media using lattice Boltzmann simulations. Water Resour. Res. 49(12), 8531-8538 (2013)

Yoon, H., Kang, Q., Valocchi, A.: Lattice Boltzmann-based approaches for pore-scale reactive transport. Rev. Miner. Geochem. 80, 393-431 (2015) 